Title: Probabilistic near-field tsunami source and tsunami run-up distribution inferred from tsunami run-up records in northern Chile

Authors: Jun-Whan Lee (jwlee89@vt.edu), Jennifer L. Irish, Robert Weiss

Jun-Whan Lee

Department of Civil and Environmental Engineering, Virginia Tech, 750 Drillfield Dr, Blacksburg, VA, 24061, USA, ORCID: 0000-0002-6722-6843 E-mail: jwlee89@,vt.edu

Jennifer L. Irish

Department of Civil and Environmental Engineering, Virginia Tech, 750 Drillfield Dr, Blacksburg, VA, 24061, USA, ORCID: 0000-0002-2429-5953

Center for Coastal Studies, Virginia Tech, 926 W Campus Dr, Blacksburg, VA 24061, USA

Robert Weiss

Department of Geosciences, Virginia Tech, 926 W Campus Dr, Blacksburg, VA, 24061, USA, ORCID: 0000-0002-7168-5401

Center for Coastal Studies, Virginia Tech, 926 W Campus Dr, Blacksburg, VA 24061, USA

This manuscript is a non-peer reviewed preprint submitted to EarthArXiv.

The published version of this preprint is available at Journal of Geophysical Research: Oceans: https://doi.org/10.1029/2021JC017289 


\title{
Probabilistic near-field tsunami source and tsunami run-up distribution inferred from tsunami run-up records in northern Chile
}

\author{
Jun-Whan Lee ${ }^{1}$, Jennifer L. Irish ${ }^{1,3}$, Robert Weiss ${ }^{2,3}$ \\ ${ }^{1}$ Department of Civil and Environmental Engineering, Virginia Tech, 750 Drillfield Dr, Blacksburg, VA, \\ 24061, USA \\ ${ }^{2}$ Department of Geosciences, Virginia Tech, 926 W Campus Dr, Blacksburg, VA, 24061, USA \\ ${ }^{3}$ Center for Coastal Studies, Virginia Tech, 926 W Campus Dr, Blacksburg, VA 24061, USA \\ Key Points: \\ - A tsunami inversion model is proposed that can infer a tsunami source and a run- \\ up distribution from observational tsunami run-up records. \\ - This model requires only a few observational run-up records and is computation- \\ ally efficient. \\ - This model has potential for supporting accurate tsunami hazard assessment.
}

Corresponding author: Jun-Whan Lee, jwlee89@vt.edu 


\begin{abstract}
Understanding a tsunami source and its impact is vital to assess a tsunami hazard. Thanks to the efforts of the tsunami survey teams, high-quality tsunami run-up data exists for contemporary events. Still, it has not been widely used to infer a tsunami source and its impact mainly due to the computational burden of the tsunami forward model. In this study, we propose a TRRF-INV (Tsunami Run-up Response Function-based INVersion) model that can provide probabilistic estimates of a near-field tsunami source and tsunami run-up distribution from a small number of run-up records. We tested the TRRFINV model with synthetic tsunami scenarios in northern Chile and applied it to the 2014 Iquique, Chile, tsunami event as a case study. The results demonstrated that the TRRFINV model can provide a reasonable tsunami source estimate to first order and estimate tsunami run-up distribution well. Moreover, the case study results agree well with the United States Geological Survey report and the global Centroid Moment Tensor solution. We also analyzed the performance of the TRRF-INV model depending on the number and the uncertainty of run-up records. We believe that the TRRF-INV model has the potential for supporting accurate hazard assessment by (1) providing new insights from tsunami run-up records into the tsunami source and its impact, (2) using the TRRFINV model as a tool to support existing tsunami inversion models, and (3) estimating a tsunami source and its impact for ancient events where no data other than estimated run-up from sediment deposit data exists.
\end{abstract}

\title{
Plain Language Summary
}

Thanks to tsunami survey teams, there are observations of the highest elevation flooded by tsunamis in discrete locations. However, this data has not been widely used to determine where the earthquake that triggered the tsunami occurred, how large the earthquake was, and how large and extensive the floods caused by the tsunami were. In this study, we develop a new computer model that can identify the earthquake information and the flooding extent along the coastline from the discrete flood observations. The new computer model is tested for thousands of artificial earthquake scenarios and a historical earthquake event that occurred in 2014 in Chile. The results show that the new computer model can estimate the earthquake information and the flooding extent well. We believe that this new computer model can advance understanding of historical tsunami events and lead to better preparedness plans for possible future tsunamis.

\section{Introduction}

Tsunamis, mainly caused by shallow subduction-zone earthquakes, can cause severe damage to coastal communities once they occur, especially to near-field areas. To mitigate the tsunami damage and increase the resiliency of coastal communities, it is crucial to better understand a tsunami source and assess its impact. To better understand the tsunami source, tsunami inversion models, which can infer a tsunami source from observed data, have been widely developed (Satake, 2009). Depending on the input data, tsunami inversion models can be divided into three types. The first type is a tsunami inversion model that relies on seismic waveform data alone or combined with other data such as local strong motion, GPS (Global Positioning System), InSAR (Interferometric Synthetic Aperture Radar), and DART (Deep-ocean Assessment and Reporting of Tsunamis) data (e.g. Lay et al., 2011; Yokota et al., 2011; Yue et al., 2014). Instead of relying on seismic waveform data, the second type is a tsunami inversion model that uses tsunami waveforms (such as DART, tide gauge data) alone or combined with GPS and/or InSAR data (e.g. Ho et al., 2019; Romano et al., 2016; Williamson et al., 2017; Zhou et al., 2019). This methodology was first proposed by Satake (1987) and is receiving increased attention, especially after the Mw 9.0 2011 Tohoku-Oki earthquake, because one of the main reasons for enormous casualties and tsunami damage is known to be due to underesti- 
mating the earthquake's magnitude and resulting tsunami run-up by relying on the early arrival of seismic waveform data alone (Hoshiba \& Ozaki, 2014). The third type is a tsunami inversion model that uses tsunami sediment deposit data to infer the historical tsunami source, especially for the paleotsunami events (e.g. Ioki \& Tanioka, 2016; MacInnes et al., 2010; Martin et al., 2008; Nanayama et al., 2003). Once a tsunami source is estimated, a tsunami forward model - usually a high-fidelity physics-based numerical model that can simulate tsunami propagation and inundation processes from a given tsunami sourceis then used to assess the impact of tsunamis.

A tsunami run-up, the maximum ground elevation wetted by the tsunami, is one of the important characteristics to quantify the impact of a tsunami. Thanks to the tsunami survey teams such as the International Tsunami Survey Team (ITST), there are many high-quality tsunami run-up data sets for contemporary events (e.g. Arcos et al., 2019; Synolakis \& Okal, 2005). For this reason, the tsunami run-up distribution along the coastline is usually employed to validate the tsunami source and to evaluate the impact of tsunamis. However, there are only a few studies that directly used tsunami run-up data to infer a tsunami source (e.g. Fuentes et al., 2016; MacInnes et al., 2010; Piatanesi et al., 1996). One of the main reasons is the tsunami forward model's computational burden because a tsunami inversion model requires a large number of tsunami forward simulations to find a tsunami source that best matches the tsunami run-up records. Even though several tsunami forward models employed computational techniques to improve the computational efficiency, such as adaptive mesh refinement and parallelization techniques (e.g. Mandli et al., 2016; Popinet, 2015), estimating a tsunami run-up distribution using highfidelity physics-based numerical models remains computationally intensive. For this reason, Fuentes et al. (2016) and Piatanesi et al. (1996) have relied on a less accurate but faster tsunami forward model than the high-fidelity model, which estimates run-up by multiplying an amplification factor and the maximum wave height of the offshore point, to consider a large number of scenarios. On the other hand, MacInnes et al. (2010) used a high-fidelity tsunami forward model but considered only a handful of scenarios determined by expert judgment.

To overcome the computational burden of the high-fidelity physics-based numerical model, Lee et al. (2020) recently developed a tsunami forward model based on a response surface methodology, hereafter Tsunami Run-up Response Function (TRRF) model, that can rapidly estimate a near-field tsunami run-up distribution over real topography without substantial loss of accuracy, with respect to high-fidelity models. The main concept of the TRRF model is that the tsunami run-up distribution can be decomposed into (1) a leading-order contribution being modeled by fault parameters using the Okal and Synolakis (2004)'s empirical formula and (2) a regional component that is dictated by the local topography.

This study proposes a new tsunami inversion model based on the TRRF model to infer a near-field tsunami source and tsunami run-up distribution from tsunami run-up records: hereafter referred to as Tsunami Run-up Response Function-based INVersion or TRRF-INV model. This study provides the first tsunami inversion model capable of giving probabilistic estimates of tsunami source information (moment magnitude, epicenter location, fault length, fault width, average slip) from tsunami run-up records. Moreover, to our best knowledge, our work is the first attempt to provide probabilistic estimates of tsunami run-up distribution derived only from a small number of tsunami runup records. We chose the northern Chile coastal region as a study area and investigated the performance of the TRRF-INV model based on synthetic tsunami run-up records, and then we applied the TRRF-INV model to real tsunami run-up records of the $M_{W} 8.2$ 2014 Iquique, Chile, earthquake. 


\section{Study Area}

The northern Chile coastal area is an active subduction zone where the Nazca plate is being subducted under the continental South-American plate at high rates (about $63 \mathrm{~mm} /$ year, Chlieh et al., 2011) (Fig. 1). The city of Iquique, one of the important commercial and industrial urban centers in the northern Chile coastal region, is exposed to significant tsunami risk considering its inhabitants (about 184,000) and critical coastal infrastructures (González et al., 2020). Historically, large earthquakes $\left(M_{W}>8.5\right)$ occurred in 1868 and 1877 near the convergent tectonic plate interface, and the tsunamis damaged the cities in northern Chile coastal region (González et al., 2020; Kulikov et al., 2005). On April 1st, 2014, at 23:46:50 UTC, a $M_{W} 8.2$ earthquake occurred off the coast of Pisagua in northern Chile in an area known as a seismic gap (a portion of an active fault known to cause a major earthquake but not occurring for a long time.) (Hayes et al., 2014). This earthquake was detected in the form of a seismic waveform, strong motion, and GPS data, and the resulting tsunami was visually detected in several DART buoys and tide gauges (e.g. An et al., 2014; Gusman et al., 2015; Lay et al., 2014; Schurr et al., 2014). Moreover, high-quality tsunami run-up records also exist (Catalán et al., 2015). Even though the 2014 Iquique earthquake relieved some amount of the accumulated deviatoric stress, several studies pointed out that the northern Chile coastal region still can generate a large earthquake with an associated tsunami (Cesca et al., 2016; Ruiz et al., 2015).

\section{Method}

The TRRF-INV model infers a tsunami source and tsunami run-up distribution from run-up records in four steps as follows (Fig. 2):

- Step 1: Set three angles (strike, dip, rake) and earthquake depth from a pre-defined list.

- Step 2: Determine the order in which to estimate the fault parameters (epicenter latitude, epicenter longitude, fault length, fault width, average slip).

- Step 3: Repeat estimating fault parameters until one of two thresholds (see section 3.3) is satisfied.

- Step 4: Generate earthquake scenarios based on the estimated fault parameters and save possible scenarios.

The TRRF-INV model repeats these four steps and accumulates possible earthquake scenarios until all combinations defined in step 1 are considered. And lastly, the probabilistic tsunami source and tsunami run-up distribution are estimated based on the accumulated scenarios.

To run the TRRF-INV model, a pre-trained TRRF model for the study area is required. In this study, we trained the TRRF model based on physics-based numerical simulations of 729 tsunamigenic-earthquake scenarios in the northern Chile coastal region (Table 1) following Lee et al. (2020). We used the numerical model Basilisk, an efficient hydrodynamic numerical model that employs an Adaptive Mesh Refinement (AMR) technique and a parallel computing technique (Popinet, 2015). We set the $x$-axis parallel to North and $y$-axis parallel to West. We systemically simulated additional 175 scenarios to calibrate the TRRF model. Then, to validate the TRRF model, we simulated 20 random scenarios (hereafter called base scenarios), which were never used to train or calibrate the TRRF model (Supplementary Table S1). The error of the TRRF model was represented by a normalized Root Mean Square Error (NRMSE), the RMSE normalized by the maximum run-up: 


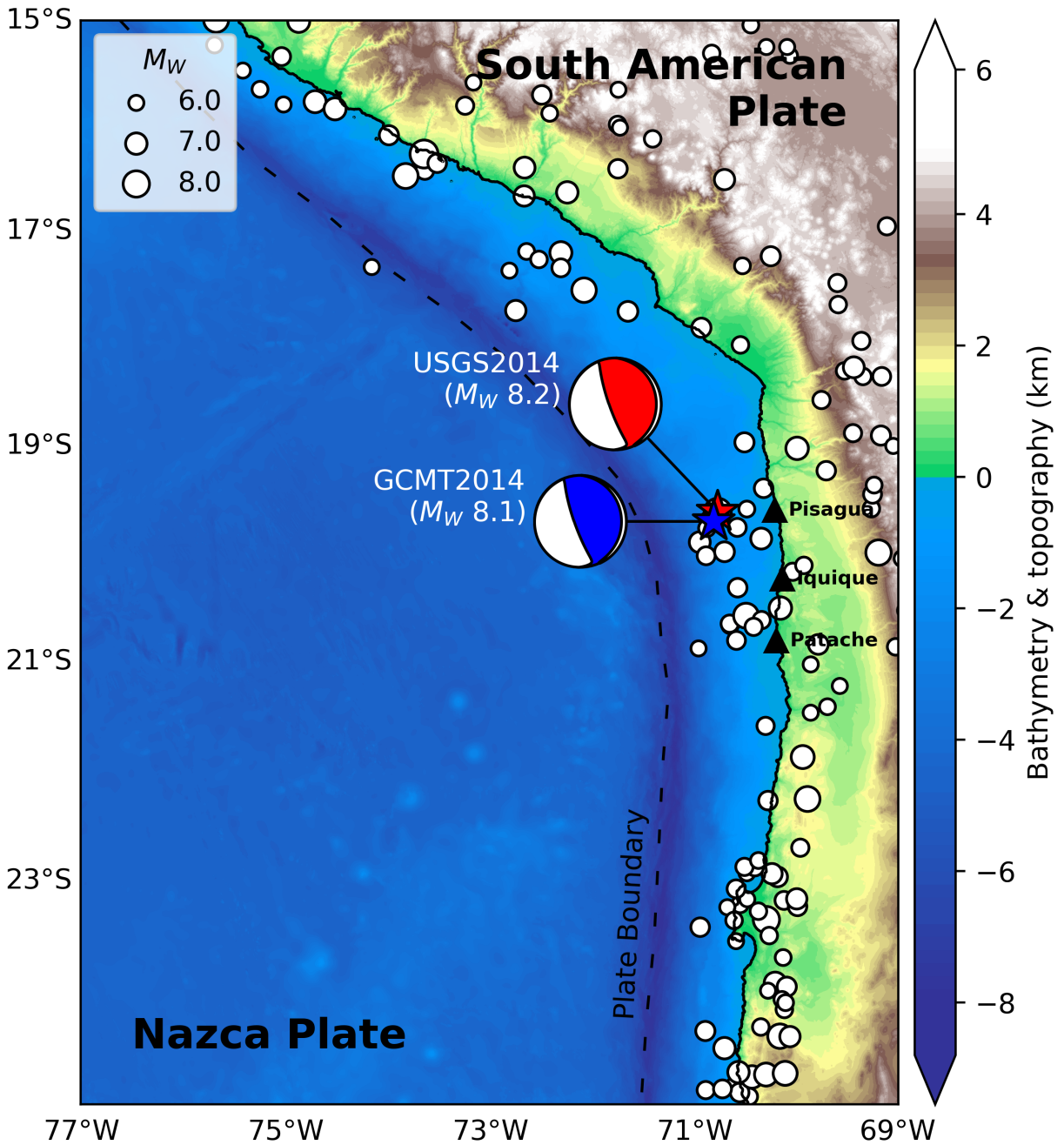

Figure 1. Map of the northern Chile coastal region. The white circles represent the historical earthquake records with magnitude larger than 6 (U.S. Geological Survey National Earthquake Information Center). The black dashed line represents the plate boundary between the Nazca and South American plates. Focal mechanisms (beachballs) and epicenters (stars) of the 2014 Iquique earthquake given by the USGS and the gCMT (Ekström et al., 2012) are plotted in red and blue color, respectively. The locations of Patache, Iquique, Pisagua are shown in black triangles. 
Table 1. Fault parameters used for TRRF training, calibration, and validation

\begin{tabular}{llllll}
\hline \multirow{2}{*}{ Fault Parameter } & \multicolumn{2}{l}{ Training } & \multicolumn{3}{c}{ Calibration \& Validation } \\
\cline { 2 - 6 } & Low & Central & High & Min & Max \\
\hline $\operatorname{LON}\left({ }^{\circ} \mathrm{W}\right)$ & 70.5 & 71.0 & 71.5 & 70.5 & 71.5 \\
$\operatorname{DIP}\left({ }^{\circ}\right)$ & 10 & 20 & 30 & 10 & 30 \\
$\operatorname{LEN}(\mathrm{km})$ & 90 & 135 & 180 & 90 & 180 \\
$W I D(k m)$ & 40 & 75 & 90 & 40 & 90 \\
$\operatorname{SLP}(\mathrm{m})$ & 2 & 4 & 6 & 2 & 6 \\
$\operatorname{DEP}(\mathrm{km})$ & 10 & 25 & 40 & 10 & 40 \\
$\operatorname{LAT}\left({ }^{\circ} \mathrm{S}\right)$ & & 20 & & 19.2 & 20.8 \\
$\operatorname{STR}\left({ }^{\circ}\right)$ & & 360 & & 340 & 360 \\
$\operatorname{RAK}\left({ }^{\circ}\right)$ & & 90 & & 70 & 110 \\
\hline
\end{tabular}

Table 2. The range of fault parameters with interval used in the TRRF-INV model

\begin{tabular}{llll}
\hline Fault Parameter & Min & Max & Interval \\
\hline $\operatorname{LON}\left({ }^{\circ} W\right)$ & 70.5 & 71.5 & 0.1 \\
$\operatorname{LAT}\left({ }^{\circ} \mathrm{S}\right)$ & 19.2 & 20.8 & 0.1 \\
$\operatorname{LEN}(\mathrm{km})$ & 90 & 180 & 5 \\
$W I D(k m)$ & 40 & 90 & 5 \\
$\operatorname{SLP}(\mathrm{m})$ & 2 & 6 & 0.5 \\
$\operatorname{DEP}(k m)$ & 20 & 30 & 5 \\
$\operatorname{STR}\left(^{\circ}\right)$ & 340 & 360 & 10 \\
$\operatorname{DIP}\left(^{\circ}\right)$ & 10 & 30 & 10 \\
$\operatorname{RAK}\left(^{\circ}\right)$ & 90 & 90 & 0 \\
\hline
\end{tabular}

$$
N R M S E=\frac{\sqrt{\frac{1}{N_{p}} \sum_{x=1}^{N_{p}}\left[R_{T}(x)-R_{p}(x)\right]^{2}}}{\max \left[R_{p}(x)\right]} \times 100(\%)
$$

where $R_{T}(x)$ is the tsunami run-up predicted by the TRRF model, $R_{p}(x)$ is the true tsunami run-up (Basilisk predictions or observational data), and $N_{p}$ is the number of alongshore locations considered. More details on the TRRF model training, calibration, and validation can be found in Appendix A.

The TRRF-INV model also requires a pre-defined range of fault parameters (Table 2). Note that the fault-parameter range must be within the range used for TRRF model validation. The rest of the section will describe the details of the TRRF-INV model.

\subsection{Step 1: Set three angles and earthquake depth}

The TRRF-INV model sets three angles (strike $S T R$, dip $D I P$, rake $R A K$ ) and top-edge fault depth $(D E P)$ from a pre-defined list. In this study, we considered 27 combinations $\left(N_{i}=27\right)$ where three-level of $S T R, D I P, D E P$ and one $R A K$ are considered (Table 2). The range of $S T R, D I P, D E P$ was determined based on the Slab model values in northern Chile (Hayes et al., 2018). Since the NRMSE changes only up to $1 \%$ with rake angle over the range from $70^{\circ}-110^{\circ}$, we assumed a pure reverse-slip mechanism $\left(R A K=90^{\circ}\right)$. 


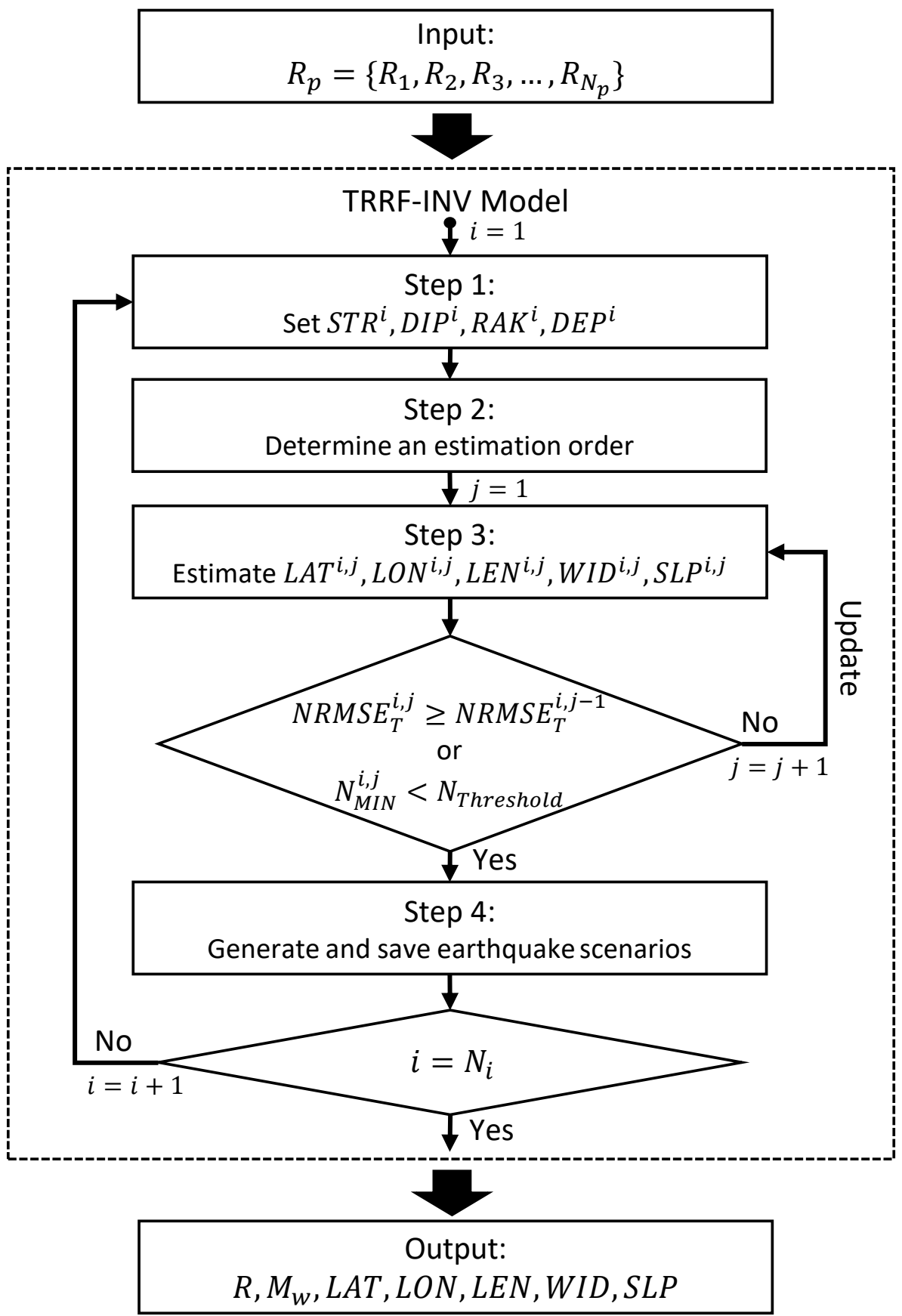

Figure 2. Computational flow of TRRF-INV model. The inputs are tsunami run-up records $\left(R_{p}\right)$ where $N_{p}$ represents the number of run-up records. The outputs are the probabilistic estimates of moment magnitude $\left(M_{W}\right)$, epicenter latitude $(L A T)$, epicenter longitude $(L O N)$, fault length $(L E N)$, fault width $(W I D)$, average slip $(S L P)$, and tsunami run-up distribution $(R) . N_{i}$ is the number of combinations of three angles and earthquake depth. $j$ is the iteration number. $N R M S E_{T}$ is a total error. $N_{M I N}$ is the minimum number of earthquake scenarios. 


\subsection{Step 2: Determine an estimation order}

Even though the TRRF model is rapid (computational time: $<1 \mathrm{~s} /$ scenario), it is still computationally intensive to simulate all possible scenarios listed in Table 2 ( $>$ 9 million scenarios). To minimize the number of TRRF simulations, the TRRF-INV model determines the order in which to estimate the fault parameters (epicenter latitude $L A T$, epicenter longitude $L O N$, fault length $L E N$, fault width $W I D$, and average slip $S L P$ ) as follows.

First, the TRRF-INV model generates scenarios for each of the five fault parameters (hereafter a reference fault parameter) as follows. The reference fault parameter varies for all values in Table 2 . The other four fault parameters vary for three-level values (minimum, maximum, and average of values listed in Table 2). The three angles and the earthquake depth are fixed to the values set in step 1. Note that the interval of five fault parameters in Table 2 was set to the value where the NRMSE change within the interval is negligible $(<0.5 \%$ point). Secondly, tsunami run-ups are estimated based on the TRRF model for each scenario, and then the NRMSE between the TRRF estimates and the run-up records is calculated. Thirdly, the scenarios where the reference fault parameter value is the same are grouped, and the mean error $(\overline{N R M S E})$ is calculated for each group. Fourthly, the maximum difference of $\overline{N R M S E}$ among groups $(\triangle \overline{N R M S E})$ is calculated. And lastly, once the $\triangle \overline{N R M S E}$ is calculated for all fault parameters $(L A T$, $L O N, L E N, W I D, S L P)$, the estimation order is defined as an order from the most sensitive fault parameter (which shows the largest $\Delta \overline{N R M S E}$ ) to the least sensitive fault parameter (which shows the smallest $\Delta \overline{N R M S E}$ ) (See example result in supplementary Text S1 and Fig. S1).

\subsection{Step 3: Estimate fault parameters}

Following the estimation order, the fault parameters are estimated until one of two stop conditions is satisfied: (1) When the error does not decrease compared to the previous iteration, (2) When the number of generated scenarios is less than the threshold. From now on, the fault parameter of the $i$ th combination (three angles and depth) of the $j$ th iteration of $k$ th estimation order will be represented as $F P_{k}^{i, j}$.

To estimate the first-order fault parameter $\left(F P_{1}^{i, j}\right)$, the TRRF-INV model generates scenarios for each value of the $F P_{1}$ in Table 2 as follows. If it is the first iteration $(j=1)$, the TRRF-INV model generates scenarios considering all combinations of threelevel values of $F P_{2}, F P_{3}, F P_{4}, F P_{5}$ used in step 2. Otherwise, the TRRF-INV model generates scenarios considering all combinations of the $(j-1)$ th estimates of the other four fault parameters $\left(F P_{2}^{i, j-1}, F P_{3}^{i, j-1}, F P_{4}^{i, j-1}, F P_{5}^{i, j-1}\right)$. The three angles and the earthquake depth are fixed to the values set in step 1. Secondly, tsunami run-ups are estimated based on the TRRF model for each scenario, and then the NRMSE between the TRRF estimates and the run-up records is calculated. Thirdly, the scenarios where the $F P_{1}$ value is the same are grouped, and the base group is defined as a group that shows the smallest mean error $\left(\min \left(\overline{N R M S E}_{F P_{1}}^{i, j}\right)\right)$. Fourthly, the model conducts the Welch's t-test between the base group and the other groups. Based on the t-test result, the estimates of the $F P_{1}^{i, j}$ are defined as the $F P_{1}$ values corresponding to the base group and the other groups that show no statistically significant $\overline{N R M S E}$ difference compared to that of the base group $(p-$ value $>0.05)$.

The other four fault parameters are estimated in the same way, following the estimation order. The only difference is that, when generating the scenarios to estimate the present-order fault parameter, the $j$ th estimates of the preceding-order fault parameters are used instead of the $(j-1)$ th estimates. For example, when estimating the fault parameter of the $i$ th combination (three angles and depth) of the $j$ th iteration of the thirdorder $\left(F P_{3}^{i, j}\right)$, the $j$ th estimates of the first and second-order fault parameters $\left(F P_{1}^{i, j}, F P_{2}^{i, j}\right)$ are used to generate the scenarios, instead of the $(j-1)$ th estimates $\left(F P_{1}^{i, j-1}, F P_{2}^{i, j-1}\right)$. 
Once all fault parameters $\left(F P_{k}^{i, j}\right)$ are estimated, the total error $\left(N R M S E_{T}^{i, j}\right)$ and the minimum number of generated earthquake scenarios $\left(N_{M I N}^{i, j}\right)$ are calculated:

$$
\begin{aligned}
& N R M S E_{T}^{i, j}=\sqrt{\sum_{k=1}^{5}\left(\min \left(\overline{N R M S E}_{F P_{k}}^{i, j}\right)\right)^{2}} \\
& N_{M I N}^{i, j}=\min \left(N_{F P_{k}}^{i, j}\right) \quad \text { where } k=1,2, \ldots, 5
\end{aligned}
$$

where $N_{F P_{k}}^{i, j}$ is the number of earthquake scenarios in the base group to estimate the $F P_{k}^{i, j}$. Then the TRRF-INV model decides whether to stop the iteration based on the two stop conditions:

$$
\begin{gathered}
N R M S E_{T}^{i, j} \geq N R M S E_{T}^{i, j-1} \\
N_{M I N}^{i, j}<N_{\text {Threshold }}
\end{gathered}
$$

The first stop condition (Eq. 4) is when the total error is not reduced compared to the previous iteration. Note that the first stop condition is only checked after the second iteration $(j \geq 2)$. The second stop condition (Eq. 5) is when the minimum number of generated earthquake scenarios is less than the threshold $\left(N_{\text {Threshold }}\right)$. The larger the threshold, the less precise the model is, and the smaller the threshold, the more likely the error distribution is not to satisfy normality. In this study, we set the threshold $\left(N_{\text {Threshold }}\right)$ to 10, balancing the model precision and normality of the error distribution. If one of the stop conditions is satisfied at the $j$ th iteration, the model stops estimating the fault parameters, and the fault parameter estimates of the $(j-1)$ th iteration are saved. Otherwise, the TRRF-INV model will repeat the procedure mentioned above (See example result in supplementary Text S2 and Fig. S2).

\subsection{Step 4: Generate and save earthquake scenarios}

The last step is to generate the earthquake scenarios based on the estimated fault parameters and save the possible scenarios where the NRMSE is smaller than the threshold. To be specific, the TRRF-INV model calculates the moment magnitude using the following equations (Hanks \& Kanamori, 1979; Aki, 1966):

$$
\begin{gathered}
M_{W}^{i}=\frac{2}{3}\left[\log \left(M_{o}^{i}\right)-9.05\right] \\
M_{o}^{i}=\mu\left(L E N^{i} \times W I D^{i} \times S L P^{i}\right)
\end{gathered}
$$

where $M_{o}$ is a seismic moment $(N m), \mu$ is the rigidity modulus of the Earth's crust $\left(N m^{-2}\right)$, and the units of fault length $(L E N)$, fault width $(W I D)$, and average slip $(S L P)$ are in meters. In this study, we assumed that the rigidity modulus $\mu$ is $3.5 \times 10^{10} \mathrm{Nm}^{-2}$ in northern Chile coastal region following Shrivastava et al. (2019). Secondly, the TRRFINV model generates scenarios considering all combinations of the estimated epicenter $\left(L A T^{i}, L O N^{i}\right)$ and the three fault parameters ( $\left.L E N, W I D, S L P\right)$ within the range of moment magnitude $\left(M_{W}^{i}\right)$. The three angles and the earthquake depth are fixed to the values set in step 1. Thirdly, tsunami run-ups are estimated based on the TRRF model for each scenario, and then the NRMSE between the TRRF estimates and the run-up records is calculated. Finally, the TRRF-INV model saves the earthquake scenarios where 
the corresponding NRMSE values are smaller than the threshold (NRMSE $E_{\text {Threshold }}^{i}$ defined as follows:

$$
N R M S E_{\text {Threshold }}^{i}=\min \left(\mathbf{N R M S E} E^{i}\right)+\alpha\left[\max \left(\mathbf{N R M S E}^{i}\right)-\min \left(\mathbf{N R M S E}^{i}\right)\right]
$$

where $\mathbf{N R M S E}^{i}$ is a list of the NRMSE values of the generated scenarios, and $\alpha$ is a constant that determines the threshold. In this study, after testing various $\alpha$ values, we set the $\alpha$ to 0.2 to balance the efficiency and the accuracy of the TRRF-INV model (Supplementary Text S3 Fig. S3).

The TRRF-INV model repeats the process from step 1 to step 4 until all combinations of three angles and earthquake depth are considered $\left(i=N_{i}\right)$. Once all combinations are considered, the TRRF-INV model estimates the probabilistic tsunami source and tsunami run-up distribution based on the accumulated earthquake scenarios.

\section{Results}

\subsection{Performance on Synthetic Scenarios}

To validate the TRRF-INV model, we generated 200 synthetic scenarios as follows. For each of the 20 base scenarios (Supplementary Table S1), we made ten scenarios by randomly selecting a few run-ups from the tsunami run-up distribution of Basilisk simulation. In this test, we fixed the number of run-up records $\left(N_{p}=20\right)$ to make the number of run-ups similar to the 2014 Chile tsunami run-up record. Note that only these 20 run-up data were provided to the TRRF-INV model as an input while the true values (the earthquake fault parameters and the tsunami run-up distribution) were intentionally concealed during the TRRF-INV model run. Here, we will first present the detailed result based on one of the synthetic scenarios (Figure 3) and then highlight the overall performance of the TRRF-INV model (Figure 4).

Figure 3 shows the results of the scenario with the smallest error for moment magnitude but the largest error for the tsunami run-up distribution among the ten random scenarios for Case 1 in Supplementary Table S1. Overall, the probabilistic estimates of tsunami source agree well with the true values for this synthetic scenario (Figure 3a). We defined the error $(e)$ as the estimated value (that showed the highest probability) minus the true value. The TRRF-INV model slightly overestimated the $M_{W}(e=0.04)$, $\operatorname{LON}\left(e=0.014^{\circ}\right), \operatorname{LAT}\left(e=0.124^{\circ}\right)$, and WID $(e=19 \mathrm{~km})$ while the model slightly underestimated the $S L P(e=-0.25 \mathrm{~m})$. Even though the $L E N$ shows a relatively large error $(e=-39 \mathrm{~km})$, the true value falls within the high probability region $(>0.6 \%)$. In Figure 3b, we plot the probabilistic estimate of the tsunami run-up distribution. The result shows that the probabilistic estimate of the TRRF-INV model agrees well with the true tsunami run-up distribution, except near the underestimated Patache area. The NRMSE between the true value and median of estimates was $8.37 \%$ when we only compared the 20 input locations $\left(N R M S E_{p}\right)$ and $8.41 \%$ when we compared the entire locations $\left(N R M S E_{t}\right)$. We defined a success ratio $(S R)$ as a ratio of the number of locations where the true run-up value falls within the range of run-up estimates (light red area in the upper panel of Fig. 3b). Moreover, the error (e) of run-up at three key locations (Patache, Iquique, Pisagua, see Fig. 1) was calculated by subtracting the true value from the median of the fitted distribution. In the case shown in Fig. 3, the TRRFINV model yields the $S R$ of $88.68 \%$ and small errors at three key locations $(|e| \leq 0.2 \mathrm{~m})$.

Figure 4 summarizes the result of all 200 synthetic scenarios. Overall, the TRRFINV model provides a reasonable first-order estimates of tsunami source, especially for the moment magnitude $M_{W}(M A E=0.04)$ and the epicenter latitude $L A T$ ( $M A E=$ $0.09^{\circ}$ ) where $M A E$ represents the mean absolute error. Moreover, the TRRF-INV model 
(a)
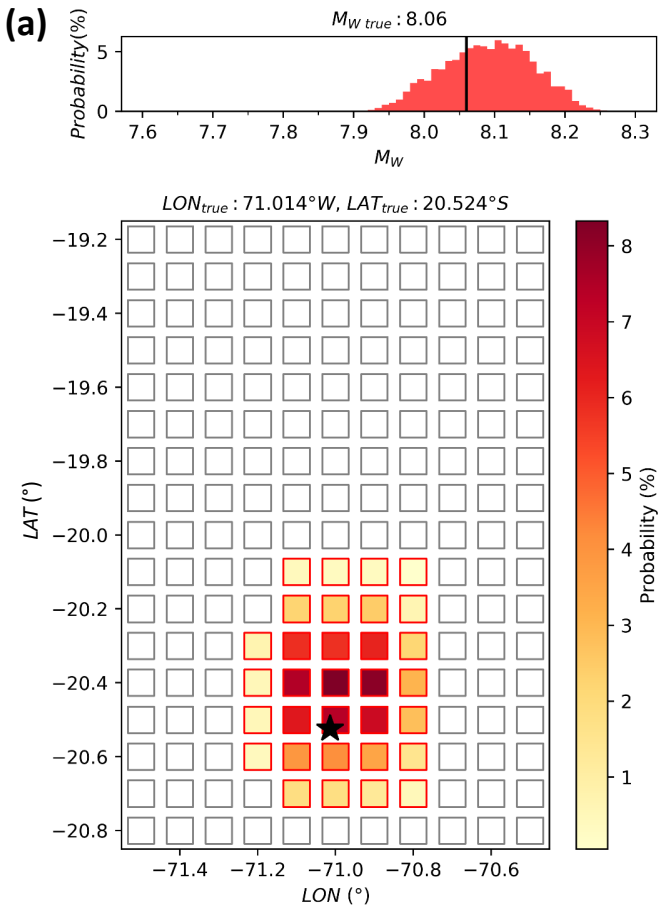

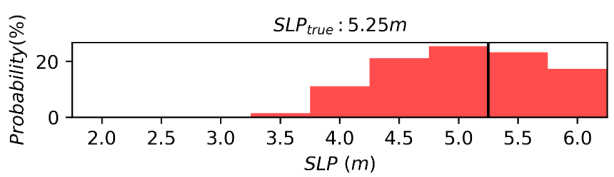

LEN true $_{\text {t }}: 179.811 \mathrm{~km}, W I D_{\text {true }}: 41.865 \mathrm{~km}$

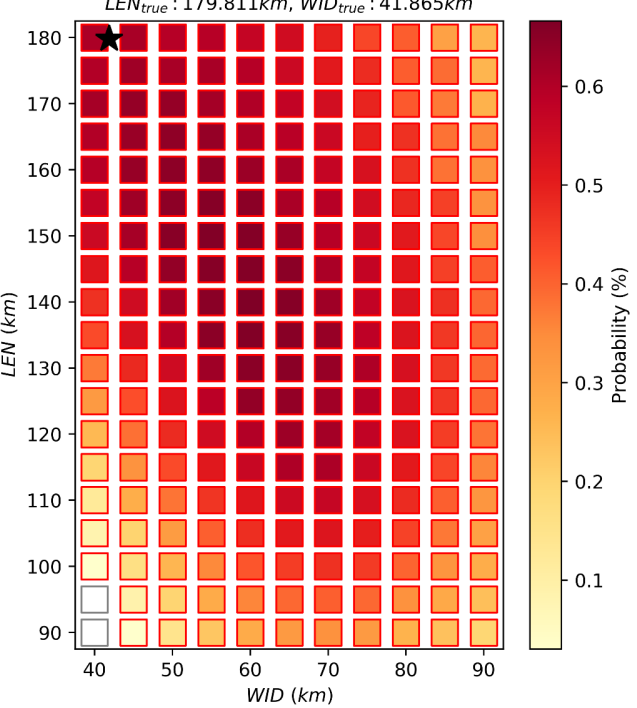

(b)

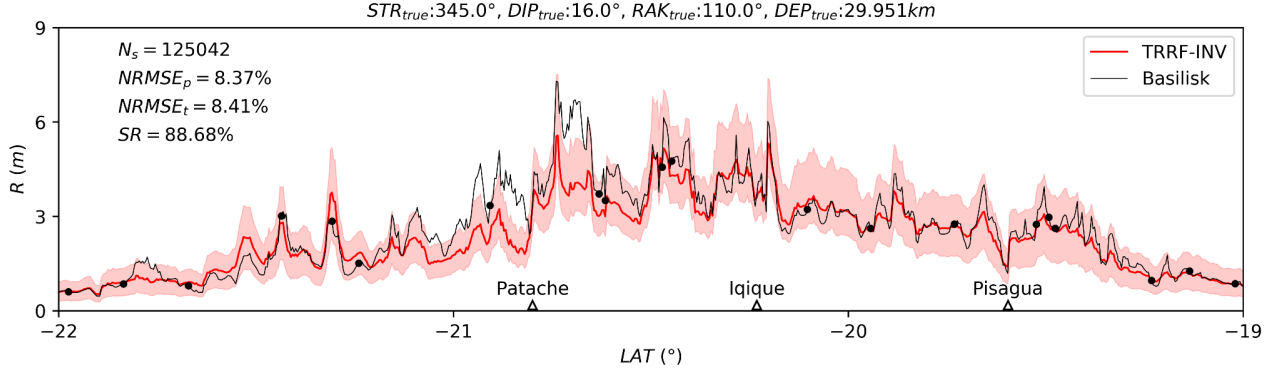

(c)
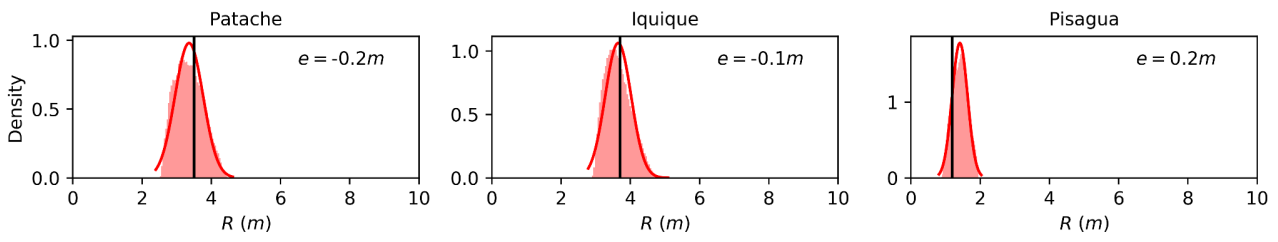

Figure 3. The TRRF-INV model outputs for the synthetic scenario. (a) Probabilistic estimates of tsunami source where the black lines and stars represent the true values. (b) Probabilistic tsunami run-up distribution. The light red area represents the full range of run-up, and the red line represents the median. The black line is true tsunami run-up distribution. The black circles are the input of the TRRF-INV model. (c) The probability density function (red curve) compared to the true run-up (black line) at three locations. 
estimates the tsunami run-up distribution quite well only with the 20 run-up data (mean $S R=95.16 \%$ ), especially in Iquique $(M A E=0.12 \mathrm{~m})$ and in Pisagua $(M A E=0.18 \mathrm{~m})$. The mean $N R M S E_{t}$ is about $6.82 \%$, which is similar to the error of the TRRF model itself.

\subsection{Performance using the 2014 Chile tsunami run-up record}

To evaluate the performance of the TRRF-INV model on a real tsunami event, we applied the TRRF-INV model to infer the tsunami source and tsunami run-up distribution from the 2014 Chile tsunami run-up records (Catalán et al., 2015) and then compared our results with the United States Geological Survey (USGS) report, the global Centroid Moment Tensor (gCMT) solution, and the other tsunami inversion model result (An et al., 2014). To match the resolution of run-up records with the grid interval of the TRRF-INV model (0.004 degrees), we used the mean value if there were more than one run-up record within a grid.

Figure 5 shows the outputs of the TRRF-INV model when using the 2014 Chile tsunami run-up records (Catalán et al., 2015) as inputs. As shown in Figure 5a, the estimated $M_{W}(=8.13)$ falls within the range between the $M_{W}$ of gCMT and that of USGS. The estimated epicenter $\left(-19.7^{\circ},-70.7^{\circ}\right)$ strongly agrees with the epicenter of USGS and that of gCMT. The relatively large probability, though not the largest, was shown near the plate boundary $\left(-19.8^{\circ},-71.5^{\circ}\right)$. Since there is no true value for the fault geometry ( $L E N, W I D, S L P)$, we compared the TRRF-INV model result with the An et al. (2014)'s finite fault slip distribution. The estimated slip $(S L P=5.5 \mathrm{~m})$ is slightly larger than the average slip of An et al. (2014). The estimated fault length ( $L E N=$ $135 \mathrm{~km})$ and fault width $(W I D=90 \mathrm{~km}$ ) resembles the fault size of An et al. (2014). Note that we defined the average slip and the fault size of the An et al. (2014)'s slip distribution based on the finite faults where the slip is larger than $3 \mathrm{~m}$. As shown in Figure $5 \mathrm{~b}$, the tsunami run-up distribution based on the TRRF-INV model is reasonably matched with the run-up records. The TRRF-INV model underestimates the observed run-up of $1.2 \mathrm{~m}$ at Patache, while the estimated run-ups at Iquique and Pisagua agree with the observations very well $(|e|=0.2 \mathrm{~m})$. Note that we used the nearest run-up records to compare the run-ups at three key locations.

To compare the performance of the TRRF-INV model and other tsunami inversion models in estimating the tsunami run-up distribution, we simulated the 2014 Iquique tsunami based on the An et al. (2014)'s tsunami source using the same Basilisk simulation condition used to develop the TRRF model in this study. The tsunami run-up distribution estimated by the An et al. (2014)'s tsunami source shows a larger error $\left(R M S E_{p}=\right.$ $1.37 \mathrm{~m}$ ) than the TRRF-INV model result $\left(R M S E_{p}=0.87 \mathrm{~m}\right)$, underestimating the tsunami run-ups, especially in the area between the Patache and Iquique, which could be critical in hazard assessment.

\section{Discussion}

Even though there was a couple of synthetic scenarios that showed a poor agreement in a tsunami source and/or run-ups, it is worth noting that the TRRF-INV model provides reasonable first-order estimates in most of the cases, given that the TRRF-INV model only used the 20 run-up data.

In the 200 synthetic-scenario test (Fig. 4), the mean absolute error $(M A E)$ of the epicenter latitude $(L A T)$ was twice smaller than that of the epicenter longitude $(L O N)$. This may be attributed to the orientation of the coastline and the earthquake fault used in this study. We assumed that the coastline was parallel to the north-south direction, and the strike direction was parallel or inclined up to $20^{\circ}$ to the coastline. In this condition, the change of the tsunami run-up distribution is more sensitive to the epicenter 

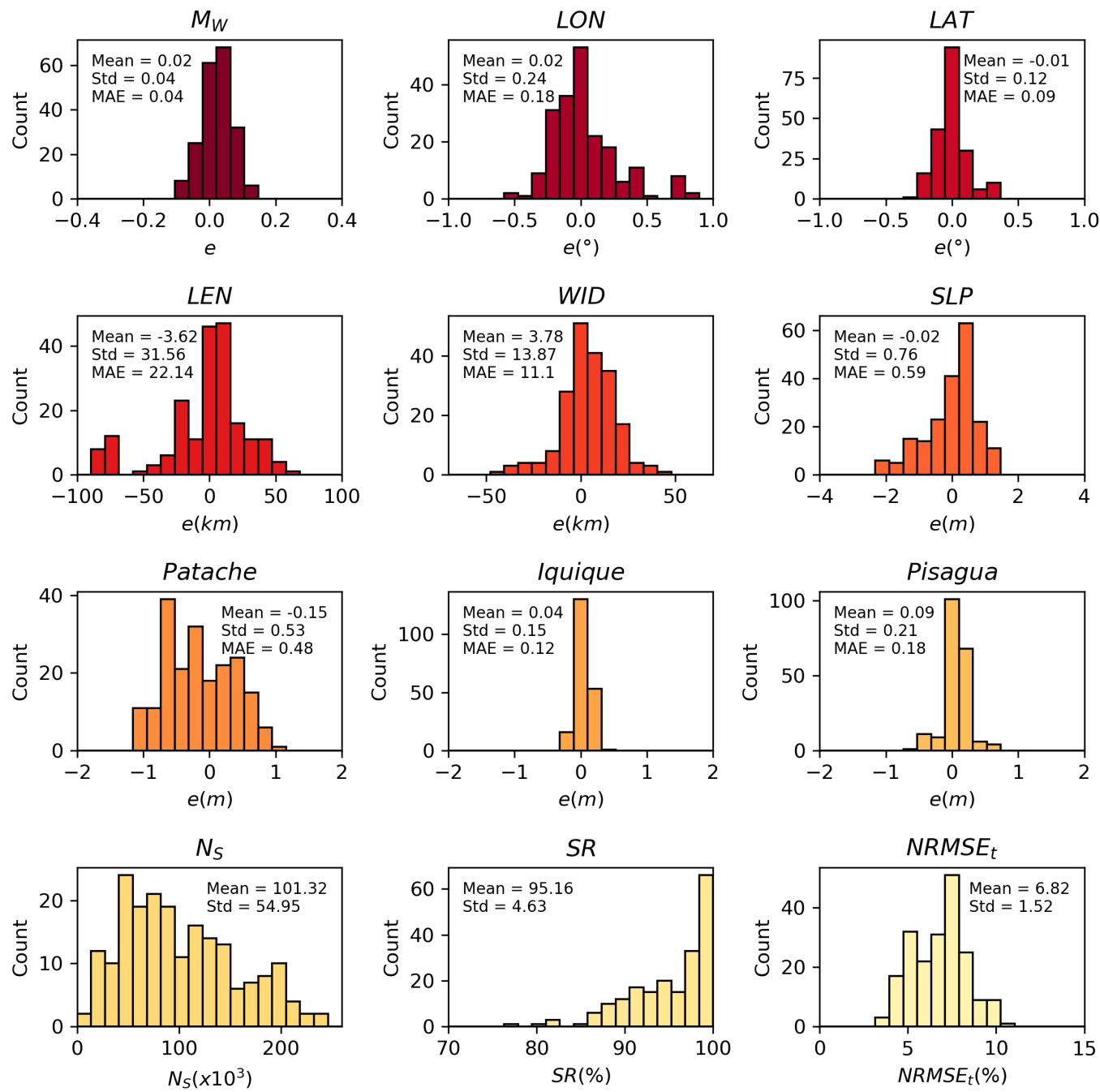

Figure 4. Performance of the TRRF-INV model based on 200 synthetic scenarios. The top three rows show the error $(e)$ distribution of moment magnitude $\left(M_{W}\right)$, epicenter longitude $(L O N)$, epicenter latitude $(L A T)$, fault length $(L E N)$, fault width $(W I D)$, average slip $(S L P)$ and the run-ups at three key locations (Patache, Iquique, Pisagua) where the $e$ is defined as the estimated value minus the true value, and the $M A E$ represents the mean absolute error. The bottom row shows the histograms of the number of filtered scenarios $\left(N_{S}\right)$, success rate $(S R)$, and the normalized root mean squared error $\left(N R M S E_{t}\right)$. The mean and the standard deviation $(S t d)$ are denoted within each panel. 
(a)
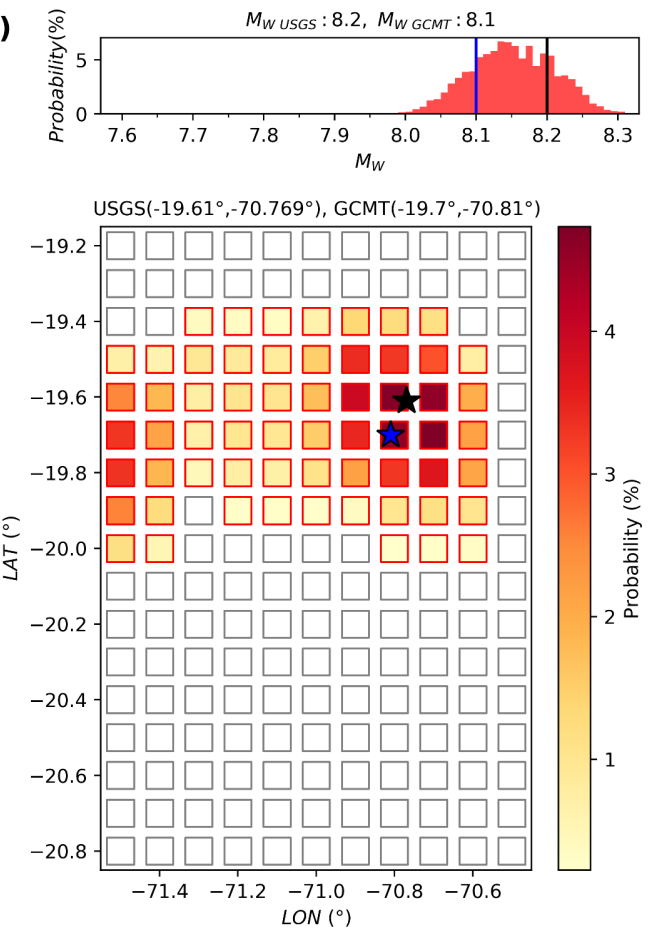

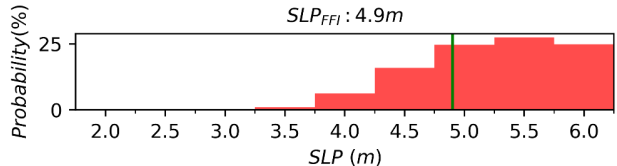

$\operatorname{SLP}(m)$

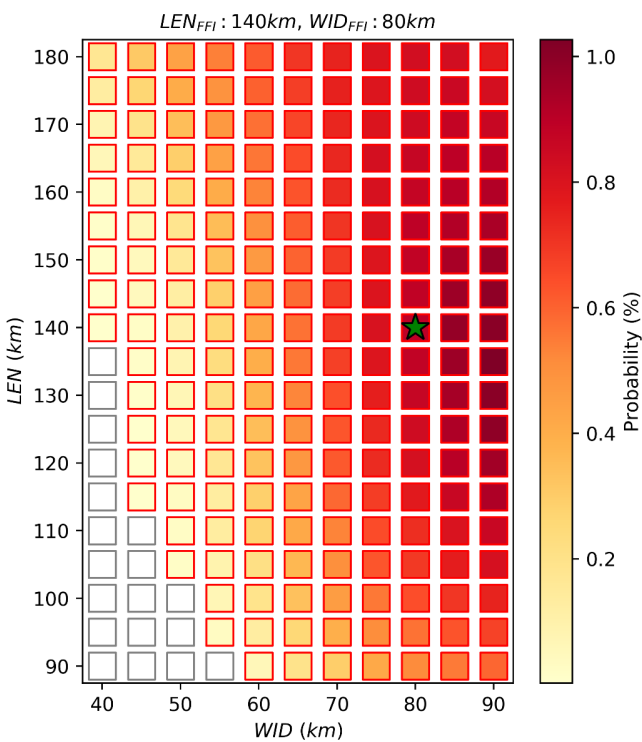

(b)

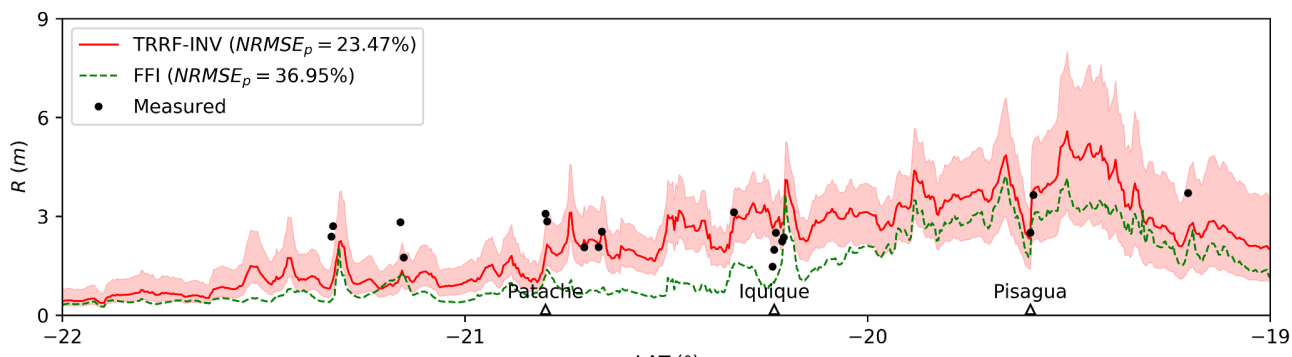

(c)
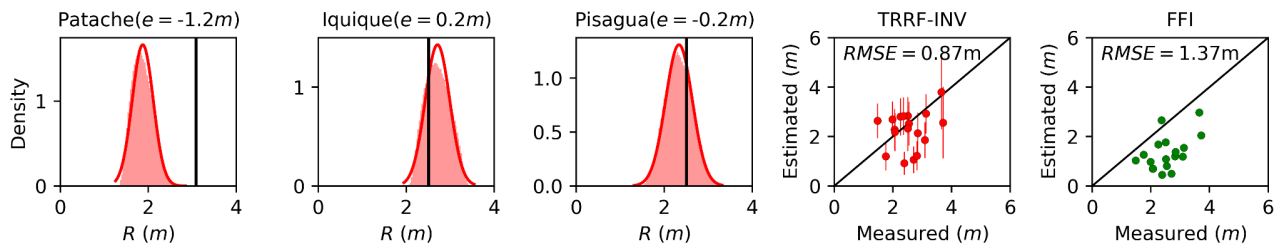

Figure 5. The TRRF-INV model outputs for the 2014 Iquique tsunami run-up records. (a) Probabilistic estimates of tsunami source. The black line and star represent the United States Geological Survey (USGS) report result. The blue line and star represent the global Centroid Moment Tensor (GCMT) solution. The green line and star represent the An et al. (2014)'s finite fault inversion (FFI) model result. (b) A probabilistic tsunami run-up distribution. The light red area represents the full range of run-up, and the red line represents the median. The green dashed line is a tsunami run-up distribution based on the FFI source, and the black circles are the 2014 Iquique tsunami run-up records. (c) The probability density function (red curve) compared to the measured run-up (black line) at three key locations (left three). The comparison of run-up between observation and the estimates of TRRF-INV model (red) and FFI (green), respectively (right two). 
latitude $(L A T)$, and thus the TRRF-INV model can distinguish a relatively small change of the epicenter latitude $(L A T)$. Similarly, the fact that the change of the tsunami runup distribution was more sensitive to the fault width $(W I D)$ than the fault length $(L E N)$ can explain the mean absolute error $(M A E)$ of the fault width $(W I D)$ that was twice smaller than that of the fault length $(L E N)$.

In Fig. 4, the TRRF-INV model shows a relatively large run-up error in Patache even though the average run-up of 20 random synthetic scenarios in Patache was similar to that in Iquique and Pisagua. The relatively large error in Patache compared to other locations was also found in the case study of the 2014 Iquique tsunami (Fig. 5b). We interpret this large error at Patache as a result of the tsunami-source direction that was mostly oriented toward the Iquique-Pisagua area (Supplementary Table S1). In this condition, tsunami waves arrived at Patache would have been relatively more affected by the secondary factors such as resonance, edge waves, and other local bathymetry effects (González et al., 2020; Catalán et al., 2015), which is not directly considered in the TRRF model, than the tsunami waves at Iquique and Pisagua.

We conducted two additional tests to analyze the sensitivity of the TRRF-INV model depending on the number and the uncertainty of run-up records (Fig. 6, Supplementary Figs. S4 to S11). First, we investigated the performance of the TRRF-INV model depending on the number of run-up records $\left(N_{p}=2,3,5,10,20,40\right)$ (Fig. 6a). For each number $\left(N_{p}\right)$, a total of 200 scenarios were considered by generating ten random scenarios for each of the 20 base scenarios (Supplementary Table S1). The results showed that the error $(e)$ decreased as the number of run-up records $\left(N_{p}\right)$ increased in general. Note that the performance is similar after $N_{p}=20$ because of the error the TRRF model itself has. Secondly, we investigated the performance of the TRRF-INV model as the uncertainty of run-up records increased (Fig. 6b). The number of run-up records $\left(N_{p}=\right.$ 20) was fixed, and the uncertainty of run-up values was generated randomly from a normal distribution with a standard deviation $\left(S t d_{U}=0 \mathrm{~m}, 0.5 \mathrm{~m}, 1.0 \mathrm{~m}\right)$ and zero mean. For the input run-ups that showed negative values after considering the uncertainty, we replaced them with zeros to prevent unrealistic negative run-up values. The results showed that the error $(e)$ increased as the uncertainty of run-up increased in general. The TRRFINV model tends to overestimate the moment magnitude $\left(M_{W}\right)$, fault length $(L E N)$, fault width $(W I D)$, average slip $(S L P)$, and run-ups at three key locations as the uncertainty increases. This is because the number of input run-ups replaced by zero is likely to increase as the uncertainty increases. These two tests suggest that the optimum conditions for achieving the convergent performance of the TRRF-INV model in northern Chile are approximately 20 observed run-up records with less than $0.5 \mathrm{~m}$ of uncertainty.

It is important to note that the performance of the TRRF-INV model depends on not only the run-up records but also several other factors such as local bathymetry/topography and earthquake slip complexity. In this study, we only tested the TRRF-INV model for up to about $M_{W} 8.3$ earthquake, assuming a uniform slip distribution in northern Chile. Also, the 2014 Iquique earthquake rupture can be considered as a compact and centered slip distribution compared to other large earthquakes (Chen et al., 2016). Thus, it is necessary to investigate further the performance of the TRRF-INV model for different regions and larger magnitude earthquakes with more complex slip distributions.

\section{Conclusions}

The capability to understand a tsunami source and its impact is crucial in robust tsunami hazard assessment. To date, several tsunami inversion models have been developed, relying on several types of measured data such as seismic waveform, strong motion, GPS, InSAR, DART, and tide gauge data. Compared to these data, a tsunami runup record has not been used widely to infer a tsunami source and tsunami run-up distribution because of the computational burden of tsunami forward simulations. In this 
(a)
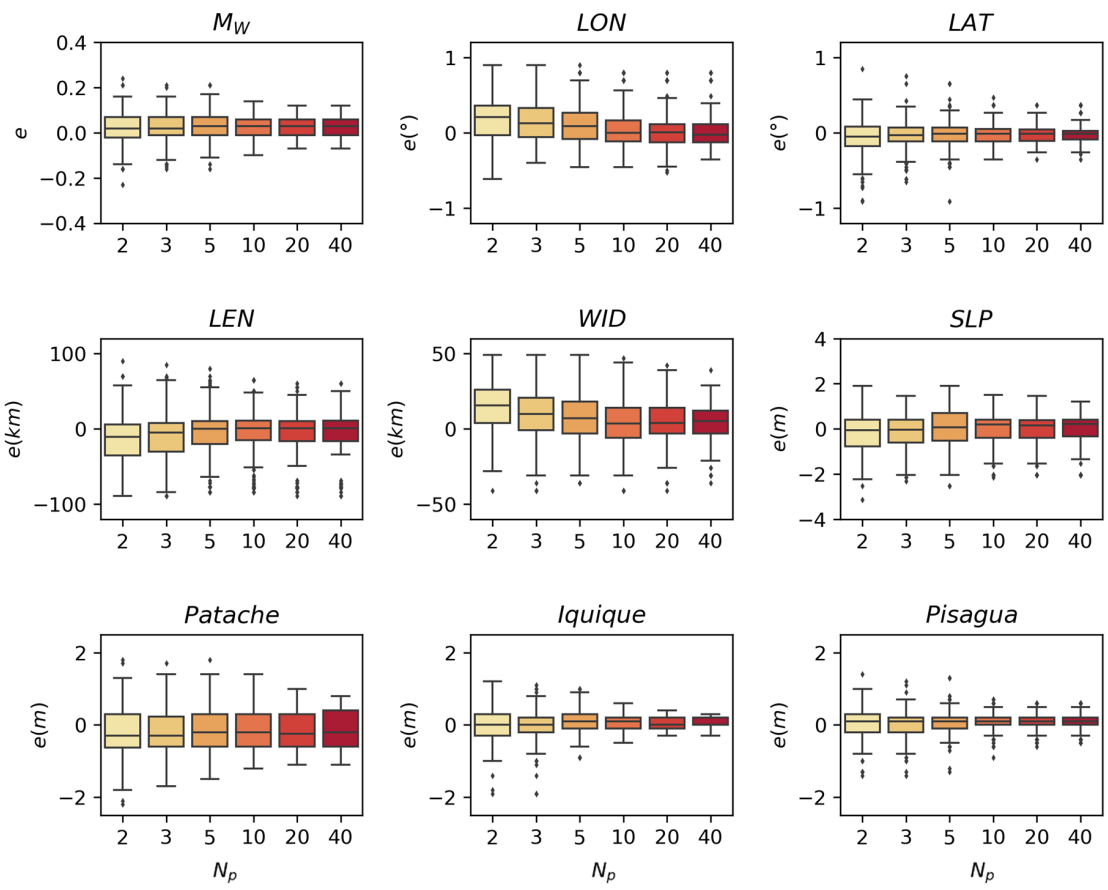

(b)
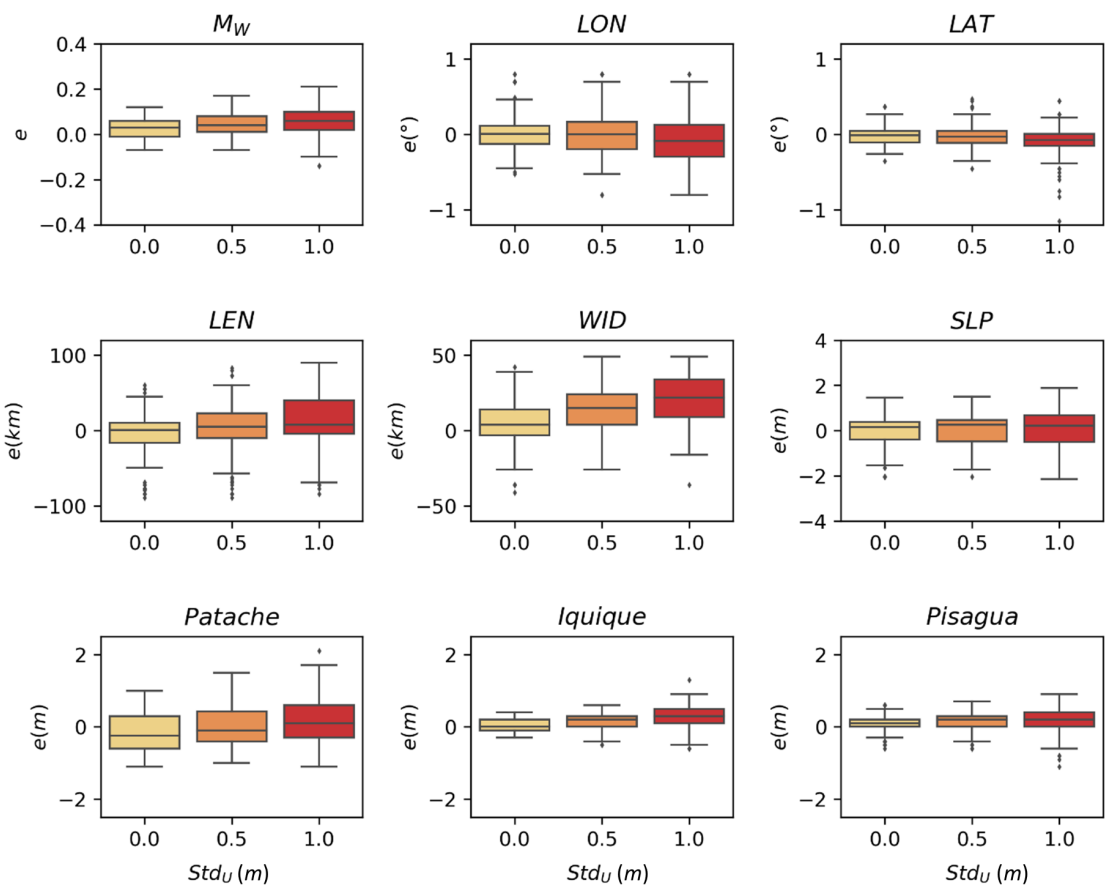

Figure 6. Performance of the TRRF-INV model depending on (a) the number of run-up records $\left(N_{p}\right)$ and (b) the uncertainty of run-up records. The error $(e)$ is defined as the estimated value minus the true value. The $S t d_{U}$ represents the standard deviation of uncertainty in meters. Each box-whisker plot consists of 200 random scenarios. The box symbol shows the interquartile range (box boundary), median (horizontal line). The lower(upper) whisker is defined as 1.5 times the interquartile range below(above) the first(third) quartile. The data beyond the whiskers is plotted as an outlier (diamond). 
paper, we propose a new tsunami inversion model, called TRRF-INV model, which can infer a probabilistic near-field tsunami source and a probabilistic tsunami run-up distribution from tsunami run-up records. The TRRF-INV model has overcome the computational burden of tsunami forward simulations by adopting the TRRF model (Lee et al., 2020) that can rapidly estimate the alongshore tsunami run-up distribution from the earthquake fault parameters. The synthetic tests based on 1,600 scenarios have confirmed that the TRRF-INV model can provide not only reasonable estimates of tsunami source to first order but also accurate tsunami run-up distribution only with 20 run-up values with less than half a meter of uncertainty. The overall agreement on the earthquake magnitude and the epicenter of the 2014 Iquique tsunami event was satisfactory compared to the USGS report and gCMT solution, which supports the effectiveness of the TRRF-INV model. We believe that the TRRF-INV model has the potential for supporting accurate hazard assessment by providing new insights from tsunami run-up records into the tsunami source and its impact. The TRRF-INV model will be beneficial to validate the tsunami source estimated from existing tsunami inversion models, or the TRRFINV model can serve as a starting point for constraining the tsunami source. Moreover, the TRRF-INV model can be potentially applied to estimate a tsunami source and its impact for ancient events where no data other than run-up estimates derived from sediment deposit data exists.

\section{Data availability Statement}

The Basilisk model used to simulate tsunamis is available at http://basilisk.fr/. The bathymetry data of the General Bathymetric Chart of the Ocean (GEBCO) is available at https://www.gebco.net/data_and_products/gridded_bathymetry_data/. The data and codes used in this paper can be accessed via repository: 10.17603/ds2-ej26-wa59.

\section{Acknowledgments}

This publication was prepared by Jun-Whan Lee using Federal funds under award NA18OAR4170083, Virginia Sea Grant College Program Project R/72155L from the National Oceanic and Atmospheric Administration's (NOAA) National Sea Grant College Program, U.S. Department. of Commerce. The statements, findings, conclusions, and recommendations are those of the author(s) and do not necessarily reflect the views of Virginia Sea Grant, NOAA, or the U.S. Department of Commerce. This material is based upon work partially supported by the National Science Foundation under Grant Nos. 1630099 and 1735139. Any opinions, findings, and conclusions or recommendations expressed in this material are those of the authors and do not necessarily reflect the views of the National Science Foundation. The authors acknowledge Advanced Research Computing at Virginia Tech for providing computational resources and technical support that have contributed to the results reported within this paper. URL: https://198.82.212.30

\section{Appendix A TRRF training, calibration, and validation}

To train the TRRF model for the northern Chile coastal region, $729\left(=3^{6}\right)$ tsunamigenicearthquake scenarios were simulated. The 729 scenarios were generated in three-level factorial design (low, central, high) of six fault parameters (LON, DIP, LEN,WID, SLP, $D E P)$ as listed in Table 1. The range of the epicenter longitude $L O N$ was determined based on the historical earthquake records in the northern Chile region (Fig. 1). The range of the fault length $L E N$, fault width WID, and slip SLP was set considering the moment magnitude $\left(M_{W}=8.2\right)$ of the 2014 Iquique earthquake. The minimum $L E N$ and the minimum WID were set to $90 \mathrm{~km}$ and $40 \mathrm{~km}$, respectively, considering the uncertainty $(1 \sigma)$ of Blaser et al. (2010)'s scaling law. The maximum $L E N$ was set to $180 \mathrm{~km}$ based on the assumption that the uniform slip distribution is applicable up to $180 \mathrm{~km}$. The maximum $W I D$ was limited to $90 \mathrm{~km}$ considering the distance between the plate 
boundary and the coastline. The range of the dip angle $D I P$ and the depth of the top edge $D E P$ were determined based on the tectonic characteristics of the northern Chile region (Shrivastava et al., 2019; Comte \& Suárez, 1995; Hayes et al., 2012). In order to apply the Okal and Synolakis (2004)'s empirical formula, the strike angle (STR) was set parallel to the coastline, and the rake angle $(R A K)$ was set to the angle that makes the strike direction perpendicular to the coastline. The epicenter latitude $(L A T)$ was fixed to the near point of the city of Iquique $\left(20^{\circ} S\right)$. The initial free surface displacement was calculated using the Okada (1985)'s equations assuming an instantaneous fault rupture. The bathymetry and topography data were from the 15 arc-second dataset (GEBCO Compilation Group, 2019). The bottom drag coefficient of a quadratic drag law was fixed to $10^{-4}$. Two hours of tsunami propagation and inundation were simulated to capture the late arrival peak run-up that could be caused by the edge waves (Catalán et al., 2015). The maximum water level was interpolated bilinearly onto a regular grid $\left(0.004^{\circ}\right.$ intervals). The origin was set to $\left(20^{\circ} \mathrm{S}, 71^{\circ} \mathrm{W}\right)$ and it was used as a reference point in the Vincenty (1975)'s formula to change the coordinate system from a spherical coordinate system to a Cartesian coordinate system.

To calibrate the TRRF model, we systemically simulated two groups of scenarios. First, 75 scenarios were simulated where the fault parameters were selected as follows. We set 15 reference scenarios by randomly selecting seven fault parameters $(L A T, L O N$, $D I P, L E N, W I D, S L P, D E P)$. For each reference scenario, five scenarios were generated where $S T R$ is $340^{\circ}, 350^{\circ}, 0^{\circ}, 10^{\circ}$, and $20^{\circ}$, respectively, while $R A K$ was fixed to $90^{\circ}$. Secondly, 100 scenarios were simulated where the fault parameters were selected as follows. We set 10 reference scenarios by randomly selecting the seven fault parameters ( $L A T, L O N, D I P, L E N, W I D, S L P, D E P)$. For each reference scenario, ten scenarios were generated where $S T R$ is $340^{\circ}, 350^{\circ}, 0^{\circ}, 10^{\circ}$, and $20^{\circ}$, respectively, while $R A K$ varies from $70^{\circ}$ to $110^{\circ}$ at intervals of $10^{\circ}$. Based on the simulation results, the TRRF model was calibrated as follows:

$$
\begin{gathered}
\theta=\left\{\begin{array}{c}
0.637 S T R-0.063 R A K-133.65^{\circ}, 340^{\circ} \leq S T R<360^{\circ} \\
0.637 S T R-0.063 R A K+95.67^{\circ}, 0^{\circ} \leq S T R \leq 20^{\circ}
\end{array}\right. \\
\lambda=-0.147 R A K+103.23^{\circ}
\end{gathered}
$$

where $\theta$ is the adjusted strike angle and $\lambda$ is the adjusted rake angle, used to consider the case where the strike direction is not parallel to the coastline and/or the slip direction is not perpendicular to the coastline. More details on the calibration procedure and how the values $(\theta$ and $\lambda)$ are used to estimate the tsunami run-up distribution can be found in Lee et al. (2020).

To validate the TRRF model, we simulated additional 20 scenarios where the fault parameters were randomly selected within the range in Table 1 . The range of six fault parameters $(L O N, D I P, L E N, W I D, S L P, D E P)$ was set to the same range used in the TRRF training. The range of $L A T$ was set based on the historical earthquake activities, including the 2014 Iquique earthquake. The range of $S T R$ was set based on the Slab model (Hayes et al., 2018). And we assumed that the $R A K$ can vary $90^{\circ} \pm 20^{\circ}$. To generate scenarios similar to the 2014 Chile earthquake, we limited the scenarios to the cases where the maximum run-up was larger than $3 \mathrm{~m}$. The fault parameters of 20 scenarios are listed in Supplementary Table S1. A comparison of tsunami run-up distribution between the TRRF model and the Basilisk model shows that the TRRF model can produce reliable run-up predictions (the range of NRMSE: $6.00 \%-13.92 \%$, mean NRMSE $=7.90 \%)$. 


\section{References}

Aki, K. (1966). Generation and propagation of G waves from the Niigata earthquake of June 16, 1964.: Part 2. Estimation of earthquake moment, released energy, and stress-strain drop from the G wave spectrum. Bulletin of the Earthquake Research Institute, University of Tokyo, 44(1), 73-88.

An, C., Sepúlveda, I., \& Liu, P. L.-F. (2014). Tsunami source and its validation of the 2014 Iquique, Chile, earthquake. Geophysical Research Letters, 41(11), 3988-3994. doi: 10.1002/2014GL060567

Arcos, N. P., Dunbar, P. K., Stroker, K. J., \& Kong, L. S. (2019). The impact of post-tsunami surveys on the NCEI/WDS global historical tsunami database. Pure and Applied Geophysics, 176(7), 2809-2829.

Blaser, L., Krüger, F., Ohrnberger, M., \& Scherbaum, F. (2010). Scaling relations of earthquake source parameter estimates with special focus on subduction environment. Bulletin of the Seismological Society of America, 100(6), 2914-2926.

Catalán, P. A., Aránguiz, R., González, G., Tomita, T., Cienfuegos, R., González, J., ... others (2015). The 1 April 2014 Pisagua tsunami: observations and modeling. Geophysical Research Letters, 42(8), 2918-2925.

Cesca, S., Grigoli, F., Heimann, S., Dahm, T., Kriegerowski, M., Sobiesiak, M., ... Olcay, M. (2016). The Mw 8.12014 Iquique, Chile, seismic sequence: a tale of foreshocks and aftershocks. Geophysical Journal International, 204(3), 1766-1780.

Chen, K., Babeyko, A., Hoechner, A., \& Ge, M. (2016). Comparing source inversion techniques for GPS-based local tsunami forecasting: A case study for the April 2014 M8.1 Iquique, Chile, earthquake. Geophysical Research Letters, 43(7), 3186-3192. doi: https://doi.org/10.1002/2016GL068042

Chlieh, M., Perfettini, H., Tavera, H., Avouac, J.-P., Remy, D., Nocquet, J.-M., ... Bonvalot, S. (2011). Interseismic coupling and seismic potential along the Central Andes subduction zone. Journal of Geophysical Research: Solid Earth, 116(B12). doi: 10.1029/2010JB008166

Comte, D., \& Suárez, G. (1995). Stress distribution and geometry of the subducting Nazca plate in northern Chile using teleseismically recorded earthquakes. Geophysical Journal International, 122(2), 419-440.

Ekström, G., Nettles, M., \& Dziewoński, A. (2012). The global CMT project 20042010: Centroid-moment tensors for 13,017 earthquakes. Physics of the Earth and Planetary Interiors, 200, 1-9.

Fuentes, M., Riquelme, S., Hayes, G., Medina, M., Melgar, D., Vargas, G., .. Villalobos, A. (2016). A Study of the $2015 \mathrm{Mw} 8.3$ Illapel earthquake and tsunami: Numerical and analytical approaches. Pure and Applied Geophysics, $173(6), 1847-1858$.

GEBCO Compilation Group. (2019). Gebco 2019 grid. doi: 10.5285/836f016a-33be -6ddc-e053-6c86abc0788e

González, J., González, G., Aránguiz, R., Melgar, D., Zamora, N., Shrivastava, M. N., ... Cienfuegos, R. (2020). A hybrid deterministic and stochastic approach for tsunami hazard assessment in Iquique, Chile. Natural Hazards, $100(1), 231-254$.

Gusman, A. R., Murotani, S., Satake, K., Heidarzadeh, M., Gunawan, E., Watada, S., \& Schurr, B. (2015). Fault slip distribution of the 2014 Iquique, Chile, earthquake estimated from ocean-wide tsunami waveforms and GPS data. Geophysical Research Letters, 42(4), 1053-1060. doi: 10.1002/2014GL062604

Hanks, T. C., \& Kanamori, H. (1979). A moment magnitude scale. Journal of Geophysical Research: Solid Earth, 84(B5), 2348-2350. 일 10.1029/ JB084iB05p02348

Hayes, G. P., Herman, M. W., Barnhart, W. D., Furlong, K. P., Riquelme, S., Benz, H. M., ... Samsonov, S. (2014). Continuing megathrust earthquake potential in Chile after the 2014 Iquique earthquake. Nature, 512(7514), 295-298. 
Hayes, G. P., Moore, G. L., Portner, D. E., Hearne, M., Flamme, H., Furtney, M., \& Smoczyk, G. M. (2018). Slab2, a comprehensive subduction zone geometry model. Science, 362 (6410), 58-61. doi: 10.1126/science.aat4723

Hayes, G. P., Wald, D. J., \& Johnson, R. L. (2012). Slab1.0: A three-dimensional model of global subduction zone geometries. Journal of Geophysical Research: Solid Earth, 117(B1). doi: 10.1029/2011JB008524

Ho, T.-C., Satake, K., Watada, S., \& Fujii, Y. (2019). Source estimate for the 1960 Chile earthquake from joint inversion of geodetic and transoceanic tsunami data. Journal of Geophysical Research: Solid Earth, 124(3), 2812-2828.

Hoshiba, M., \& Ozaki, T. (2014). Earthquake early warning and tsunami warning of the Japan Meteorological Agency, and their performance in the 2011 off the pacific coast of Tohoku Earthquake (Mw9.0). In F. Wenzel \& J. Zschau (Eds.), Early warning for geological disasters: Scientific methods and current practice (p. 1-28). Berlin, Heidelberg: Springer Berlin Heidelberg.

Ioki, K., \& Tanioka, Y. (2016). Re-estimated fault model of the 17th century great earthquake off Hokkaido using tsunami deposit data. Earth and Planetary Science Letters, 433, 133 - 138. doi: https://doi.org/10.1016/j.epsl.2015.10.009

Kulikov, E. A., Rabinovich, A. B., \& Thomson, R. E. (2005). Estimation of tsunami risk for the coasts of Peru and northern Chile. $\quad$ Natural Hazards, 35(2), 185209.

Lay, T., Ammon, C. J., Kanamori, H., Xue, L., \& Kim, M. J. (2011). Possible large near-trench slip during the $2011 \mathrm{Mw} 9.0$ off the Pacific coast of Tohoku Earthquake. Earth, planets and space, 63(7), 32.

Lay, T., Yue, H., Brodsky, E. E., \& An, C. (2014). The 1 April 2014 Iquique, Chile, Mw 8.1 earthquake rupture sequence. Geophysical Research Letters, 41(11), 3818-3825. doi: 10.1002/2014GL060238

Lee, J.-W., Irish, J. L., \& Weiss, R. (2020). Rapid prediction of alongshore runup distribution from near-field tsunamis. Natural Hazards, 104 (2), 1157-1180. doi: $10.1007 / \mathrm{s} 11069-020-04209-\mathrm{z}$

MacInnes, B. T., Weiss, R., Bourgeois, J., \& Pinegina, T. K. (2010). Slip distribution of the 1952 Kamchatka Great Earthquake based on near-field tsunami deposits and historical records. Bulletin of the Seismological Society of America, 100(4), 1695-1709.

Mandli, K. T., Ahmadia, A. J., Berger, M., Calhoun, D., George, D. L., Hadjimichael, Y., ... LeVeque, R. J. (2016). Clawpack: building an open source ecosystem for solving hyperbolic PDEs. PeerJ Computer Science, 2, e68. doi: $10.7717 /$ peerj-cs.68

Martin, M. E., Weiss, R., Bourgeois, J., Pinegina, T. K., Houston, H., \& Titov, V. V. (2008). Combining constraints from tsunami modeling and sedimentology to untangle the 1969 Ozernoi and 1971 Kamchatskii tsunamis. Geophysical Research Letters, 35(1). doi: 10.1029/2007GL032349

Nanayama, F., Satake, K., Furukawa, R., Shimokawa, K., Atwater, B. F., Shigeno, K., \& Yamaki, S. (2003). Unusually large earthquakes inferred from tsunami deposits along the Kuril trench. Nature, 424(6949), 660-663.

Okada, Y. (1985). Surface deformation due to shear and tensile faults in a halfspace. Bulletin of the seismological society of America, 75 (4), 1135-1154.

Okal, E. A., \& Synolakis, C. E. (2004). Source discriminants for near-field tsunamis. Geophysical Journal International, 158(3), 899-912. doi: 10.1111/j.1365-246X .2004.02347.x

Piatanesi, A., Tinti, S., \& Gavagni, I. (1996). The slip distribution of the 1992 Nicaragua Earthquake from tsunami run-up data. Geophysical Research Letters, 23(1), 37-40. doi: 10.1029/95GL03606

Popinet, S. (2015). A quadtree-adaptive multigrid solver for the Serre-Green-Naghdi equations. Journal of Computational Physics, 302, 336-358. doi: 10.1016/j.jcp .2015 .09 .009 
Romano, F., Piatanesi, A., Lorito, S., Tolomei, C., Atzori, S., \& Murphy, S. (2016). Optimal time alignment of tide-gauge tsunami waveforms in nonlinear inversions: Application to the 2015 Illapel (Chile) earthquake. Geophysical Research Letters, 43(21), 11-226.

Ruiz, J., Fuentes, M., Riquelme, S., Campos, J., \& Cisternas, A. (2015). Numerical simulation of tsunami runup in northern chile based on non-uniform k-2 slip distributions. Natural Hazards, 79(2), 1177-1198.

Satake, K. (1987). Inversion of tsunami waveforms for the estimation of a fault heterogeneity: Method and numerical experiments. Journal of Physics of the Earth, 35(3), 241-254.

Satake, K. (2009). Tsunamis, Inverse Problem of. In R. A. Meyers (Ed.), Encyclopedia of complexity and systems science (pp. 9631-9644). New York, NY: Springer New York. doi: 10.1007/978-0-387-30440-3\_570

Schurr, B., Asch, G., Hainzl, S., Bedford, J., Hoechner, A., Palo, M., ... others (2014). Gradual unlocking of plate boundary controlled initiation of the 2014 Iquique earthquake. Nature, 512(7514), 299-302.

Shrivastava, M. N., González, G., Moreno, M., Soto, H., Schurr, B., Salazar, P., \& Báez, J. C. (2019). Earthquake segmentation in northern Chile correlates with curved plate geometry. Scientific reports, 9(1), 1-10.

Synolakis, C., \& Okal, E. (2005). 1992-2002: Perspective on a Decade of PostTsunami Surveys. In K. Satake (Ed.), Tsunamis: Case Studies and Recent Developments (pp. 1-29). Dordrecht: Springer Netherlands. doi: 10.1007/1-4020 $-3331-1 \backslash-1$

Vincenty, T. (1975). Direct and inverse solutions of geodesics on the ellipsoid with application of nested equations. Survey review, 23(176), 88-93.

Williamson, A., Newman, A., \& Cummins, P. (2017). Reconstruction of coseismic slip from the 2015 Illapel earthquake using combined geodetic and tsunami waveform data. Journal of Geophysical Research: Solid Earth, 122(3), 21192130. doi: 10.1002/2016JB013883

Yokota, Y., Koketsu, K., Fujii, Y., Satake, K., Sakai, S., Shinohara, M., \& Kanazawa, T. (2011). Joint inversion of strong motion, teleseismic, geodetic, and tsunami datasets for the rupture process of the 2011 Tohoku earthquake. Geophysical Research Letters, 38(7). doi: 10.1029/2011GL050098

Yue, H., Lay, T., Rivera, L., An, C., Vigny, C., Tong, X., \& Báez Soto, J. C. (2014). Localized fault slip to the trench in the 2010 Maule, Chile $\mathrm{Mw}=8.8$ earthquake from joint inversion of high-rate GPS, teleseismic body waves, InSAR, campaign GPS, and tsunami observations. Journal of Geophysical Research: Solid Earth, 119(10), 7786-7804. doi: 10.1002/2014JB011340

Zhou, T., Meng, L., Xie, Y., \& Han, J. (2019). An adjoint-state full-waveform tsunami source inversion method and its application to the 2014 Chile-Iquique tsunami event. Journal of Geophysical Research: Solid Earth, 124(7), 67376750. doi: 10.1029/2018JB016678 